\title{
Search Engine Optimization Techniques for Malaysian University Websites: A Comparative Analysis on Google and Bing Search Engine
}

\author{
Asim Shahzad ${ }^{\#}$, Nazri Mohd Nawi”, Edi Sutoyo ${ }^{*}$, Muhammad Naeem $^{\$}$, Arif Ullah ${ }^{\#}$, Sundas Naqeeb \\ Muhammad Aamir $\$$ \\ \# Faculty of Computer Science and Information Technology, Universiti Tun Hussein Onn Malaysia. \\ E-mail:nazri@uthm.edu.my \\ *School of Industrial Engineering, Telkom University, 40257 Bandung, West Java, Indonesia \\ $\$$ Department of Information Technology, Abbottabad University of Science \& Technology, KPK, Pakistan.
}

\begin{abstract}
Search Engine Optimization (SEO) plays a very vital role in the development of professional websites. There are some search engines available on the internet such as Yahoo, Ask.com, AOL.com, Baidu, and Bing. Among which Google is the most widely used search engine. Each search engine uses different SEO technique and algorithm, which not only forms the foundation of SEO but affects the position of a website in organic search results as well. As Google modify its algorithm about 500 or more times per year, the web design and internet also evolves dynamically because of changes in SEO techniques and algorithms. However, how well Malaysian universities websites are optimized for other search engines is questionable particularly the critical differences between search engine ranking techniques and algorithms. This research paper tends to answer these vital questions by proposing a comparative analysis of Bing and Google on some Malaysian universities website, analyzing their search engine optimization parameters and outcomes of using Microsoft Bing as compared to its primary competitor, Google.
\end{abstract}

Keywords—search engine optimizations; web services; keywords analysis; search ranking algorithms; search engines

\section{INTRODUCTION}

In this new era of information technology, there is a vast amount of unstructured data exist on the World Wide Web. Search Engines (SE) are complicated software that helps the user to find the required information on the internet. The search engine is like an answering machine, which can provide very accurate information that makes a search engine successful. Users will always use the one search engine, which they get the most suitable information from. Existing search engines like Bing, Google, AOL, Yandex, Ask.com, etc. have established different search engine optimization algorithms to rank web page results and offer these results to the user.

It is a business secret of how search engines are used to rank web pages on the internet and what are their ranking algorithms. Moreover, the knowledge about search engine ranking algorithms is based on literature and SEO expert's assumptions. Google search engine has a very complicated algorithm where the algorithm has more than 211 on and offpage factors, which have a direct effect on the importance of positioning of the resultant websites as well as having content nearest to user's query [1].
For example, the first place on Google's search engine results pages (SERP) brings $33 \%$ clicks, whereas second place brings $17.7 \%$ of total clicks from search engine result pages [1]. It means that if 80.000 queries in Malaysia for word 'online admission' are submitted per month, the result of the first position could receive 26.000 of all clicks from the users [2]. Therefore, it is more likely that web page content publishers will have their web page as higher as they could on SERP. The higher the position of a website on SERP, the higher will be a chance of website visitors.

According to [3], SEO is a continuous process that helps the website in getting a better position on SERP. There are two types of SEO techniques on-page and off-page [4]. The first type of SEO method can be used directly on any web page and is known as on-page SEO. The second type of technique is applied out of web page is known as off-page SEO.

However, before doing anything else, it is essential to highlight the significance of best quality content on websites that based on fundamentally distinct, educational and fascinating for the website visitors [5]. The meaning of best quality content is, content must be fundamentally distinct, educational and fascinating for the website visitors. The quality content will hold the attention of the user for long 
periods of time and will sometimes motivate the visitors to share such content within their social circles or on social media [6], [7]. Sharing web page contents with friends in social circles is an off-page SEO done by website visitor without any cost. While poor web content will eventually decrease, the visitor's attention and they will not spend much time on such websites [8].

Today's search engines are intelligent such that they can learn from the experience of the users. If a lot many visitors to a particular website leave from the first page within a short amount of time, that page falls on SERP [9]. If the posted content is of high quality, it would not require much SEO efforts. If content publishers come up with quality content, SEO will help in better positioning of their websites.

\section{MATERIAL AND METHOD}

The SEO process has four main phases, which are keyword analysis, on-page search engine optimization, offpage search engine optimization and measuring outcome [10], $s$. If in the end, measuring results show a lesser amount of success regarding SEO, previous phases are repeated with a new strategy [11], [12].

\section{A. Keywords Analysis}

SEO begins with developing search keywords policy. The search keyword is the word or combination of words, which are entered by the users in the search engine. There are specialized online tools available on the internet called keyword analysis tools, which help the SEO experts in finding the suitable words, their synonyms, variants of such keywords and key phrases for all such keywords. Some of these tools provide the users with search volume estimation every month. Identifying the competitor is the critical phase of analysis in obtaining high ranking in search engine result pages with a single common phrase and can be impossible for the new website if a lot of recognized competitors already using this keyword. To get a top ranking position in search engine results pages is relatively more comfortable if the long tail keyword (combination of two, three or four words) is used. The longer the search term, the smaller the volume of the search term.

\section{B. On-page Search Engine Optimization}

A few of the vital elements of on-page optimization are [13]:

- Description and title tags

- Heading and link organization

- Keywords consistency \& density

Results obtained from keywords analysis are applied in search engine optimization. The title tag is used for the website description, which is shown to visitors in search engine result pages.

It is worthwhile to come up with noticeable and concise title tag (not more than 80 characters) which contains the keywords, which exactly match, or variation of user's inquiry. It is a known fact that the meta description tags are usually found in SERP [4]. Therefore, creating a brief description can be beneficial in earning more visitors to the web page. HTML header tags play an essential part in the making the longer text readable. Using such URLs, which can be easily read by people and do not contain query strings and parameter, help the search engines to crawl pages on the website [5]. Such URLs, which contain essential keywords, are expressive for users who can quickly look them up in search engine result pages and shared content on social networking sites.

Relevant keywords should appear in the description, headings, URL, title and, apparently, in web page content. It is believed that keywords should be the same, or there should be the perfect keywords density in a web page. Keywords should be used sensibly [14]. There will be a negative impact on the ranking if the keyword density is high. Furthermore, the time taken to load a page is also vital on page SEO factor that affects user experience. Quick page loading is best, and it can be achieved by

- Using gzip compression and caching techniques

- Minifying JavaScript, CSS, and HTML

- Ranking important content.

\section{Off-page Search Engine Optimization}

Backlink from another site to a page is considered as a vote by a search engine [3]. More backlinks do not necessarily mean good ranking. However, the critical factor is the standard of the link. There are different techniques by using which search engines can calculate the importance of inbound links. Inbound links coming from trustworthy or reliable websites have the higher importance [6]. More important for the book's website has a backlink from an education-related web page than from a sports-related web page. Search engines prefer backlinks from trusting and reliable websites because getting these backlinks are very difficult.

Recently search engines hugely appreciated the anchor text (text that appears highlighted in a hyperlink), but now ranking factors are different [15]. Same anchor texts are extremely used in links by SEO experts for different websites, but this was the indicator to search engines that SEO experts [16] can only create such kind of link. Now in search engine optimization society, there is a belief that poorly structured hyperlinks (distinction in anchor text, without anchor text links, anchor text with keyword 'click here') are highly preferred by search engines [17]. From poorly structured hyperlinks, search engines are guessing that it could be the non-professional users who created the links who knows nothing about anchor text. A combination of the above two types of backlinks is known best now in the SEO community [18].

Backlinks from social media are also an essential element of off page SEO technique. Search engines calculate the website relevancy by activities on social media. Authority of a website is increasing due to higher social media activity, and it is directly driving the traffic to the website.

\section{Measuring Outcomes}

Measuring outcomes is a significant factor in efficient and well-organized search engine optimization. Traffic monitoring, keyword rank tracking, inbound and outgoing links tracking and search engine optimization cost (money 
and time) are inputs for improvement, planning, and adaptation a new search engine optimization cycle.

\section{E. Google versus Bing SEO}

Famous search engines (SE) for web page optimization publish guidelines for webmasters. Some general recommendations from Google are as below [19]

- Create valuable, useful, full of information website with clear text links and hierarchy

- Do not mislead website users

- Do not create a website for SE, create it for users.

- Improve page load time, use robots.txt and sitemaps

- Avoid link schemes, hidden links, cloaking and sneaky redirects.

Some of Bing guidelines are as below [20]:

- Bing considers few things as a symbol of reputation, which are incoming links, detailed, easy to search, clear, appealing and vibrant content that give the essential information to the users.

- Page load time has a significant impact on user's satisfaction, reduce the page load time.

- Avoid link spamming and link buying

- Avoid duplicate contents across different URLs it can lead Bing losing trust in those URLs.

- Use header tags, page description, and title.

There are some techniques, which try to mislead the users and (SE) search engines. Such techniques are called blackhat SEO techniques. Search engines always stress avoiding black hat SEO techniques for example [21].

- Malicious page creation such as Trojans, installing viruses, or phishing

- Using irrelevant keywords on web pages

- Submitting automated queries to (SE) search engines.

- Link schemes participation

- Pages creation with fake contents scraped content or automatically generated contents

It is not easy to define the difference between the SEO ranking factors of Google and Bing that makes each distinctive [22]. However, by comparing different resources on the internet, finally, we obtained some findings [23] and can be seen in Table 1 .

Google is a leading search engine in the market [24]. In 2016, 96.7\% of users used the Google. Almost two percent users use Bing and almost one percent users in Malaysia use Yahoo. Majority of Malaysian search engine optimization efforts are directed towards Google. The share of Bing in the United States market was $10.35 \%$ in 2016.

TABLE I

GOOGLE AND BING SEARCH ENGINE OPTIMIZATION RANKING FACTORS

\begin{tabular}{|l|l|l|}
\hline & $\begin{array}{l}\text { Google Ranking } \\
\text { Factors }\end{array}$ & Bing Ranking Factors \\
\hline $\begin{array}{l}\text { Indexing } \\
\text { (images, } \\
\text { files, web \&, } \\
\text { etc) }\end{array}$ & $\begin{array}{l}\text { Google is } \\
\text { Indexing every } \\
\text { file, image and } \\
\text { page }\end{array}$ & $\begin{array}{l}\text { Only index the pages } \\
\text { with ranking authority }\end{array}$ \\
\hline $\begin{array}{l}\text { Natural } \\
\text { Links }\end{array}$ & $\begin{array}{l}\text { Emphasize more } \\
\text { on natural links }\end{array}$ & $\begin{array}{l}\text { Emphasize less on } \\
\text { natural links }\end{array}$ \\
\hline $\begin{array}{l}\text { New } \\
\text { contents }\end{array}$ & $\begin{array}{l}\text { Fresh contests are } \\
\text { more important }\end{array}$ & $\begin{array}{l}\text { Fresh contents are less } \\
\text { important }\end{array}$ \\
\hline
\end{tabular}

\begin{tabular}{|l|l|l|}
\hline Caching & $\begin{array}{l}\text { Can handle the } \\
\text { larger pages }\end{array}$ & $\begin{array}{l}\text { Bing is caching only } \\
\text { first } 100 \mathrm{~KB} \text { of most of } \\
\text { the pages }\end{array}$ \\
\hline Domain age & $\begin{array}{l}\text { Domain age is } \\
\text { less important }\end{array}$ & $\begin{array}{l}\text { Domain age is highly } \\
\text { important }\end{array}$ \\
\hline $\begin{array}{l}\text { Title } \\
\text { keywords }\end{array}$ & $\begin{array}{l}\text { Emphasize less on } \\
\text { keywords, } \\
\text { considers } \\
\text { keyword in the } \\
\text { title of the web } \\
\text { page as a factor } \\
\text { for ranking. }\end{array}$ & $\begin{array}{l}\text { Emphasize most on } \\
\text { keywords, but keyword } \\
\text { position in the title is } \\
\text { not important. }\end{array}$ \\
\hline $\begin{array}{l}\text { Keywords } \\
\text { exact } \\
\text { matching }\end{array}$ & $\begin{array}{l}\text { Google can } \\
\text { understand the } \\
\text { synonyms for a } \\
\text { keyword that is } \\
\text { why exact } \\
\text { matching is not } \\
\text { necessary. }\end{array}$ & $\begin{array}{l}\text { Keywords exact } \\
\text { matching is necessary }\end{array}$ \\
\hline Flash & $\begin{array}{l}\text { Flash is less } \\
\text { friendly }\end{array}$ & Flash is most friendly \\
\hline
\end{tabular}

Since the United States, market decides the international trends, so it is evident that Bing is also an outstanding search engine and not unrelated [25].

\section{RESULTS AND DISCUSSION}

In order to decide how Malaysian universities websites are optimized and what types of outcomes are accomplished on two main search engines, we selected five important universities websites in Malaysia:

- um.edu.my (University of Malaya),

- utm.my (Universiti Teknologi Malaysia),

- usm.my (Universiti Sains Malaysia),

- uthm.edu.my (Universiti Tun Hussein Onn Malaysia) and,

- ump.edu.my (Universiti Malaysia Pahang).

A short list of only five websites is selected just because of not losing the focus by analyzing too many similar websites. The website selection criteria were site reputation, search engine optimization approach used by website and website design. Universities websites are selected because many national and international students are searching for information regarding research conferences, university grants and admission information in Malaysian universities using different search engines. The fundamental search engine optimization parameters selected for this comparison are Google Page Rank, Alexa Page Rank, Woorank grade, number of indexed pages in Google and Bing, Twitter followers, Facebook likes, and page load time of the website. Tools used for results calculation and analysis are Semrush, Link-Assistant SEO, Webrank, PowerSuite, and Woorank.

\section{A. Google PageRank}

Google uses the PageRank algorithm to determine the importance of a web page. This algorithm determines which pages appear in search engine results pages (SERP). In slang term, PageRank is also known as "Google juice." According to Google officials: The number of quality web pages that are linked to website primarily determines PageRank. Google considers this type of inbound link a vote of 
assurance. The underlying supposition is that most famous sites are expected to get more inbound links from other good sites [26]. Google PageRank is ranging from zero to 10, where 10 is the best and zero being the worst PageRank.

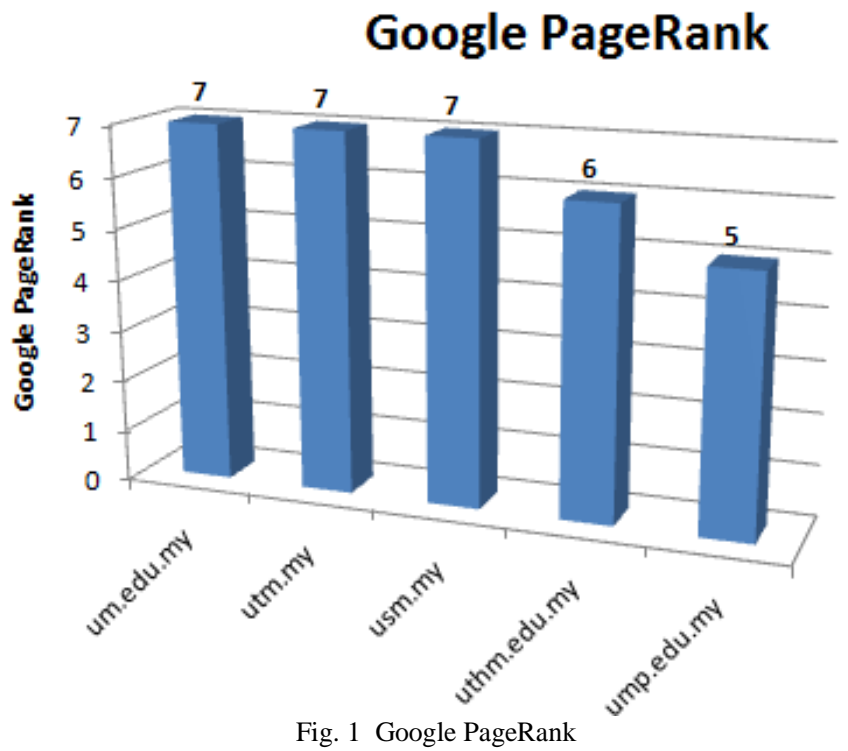

As Google PageRank is one of the essential search engine optimization factors, so we calculated the Google PageRank for all universities' websites using Google PageRank calculator. Highest PageRank score means that the website is optimized more accurately for search engines while lower PageRank score means that the website is poorly optimized for search engines. Fig. 1 demonstrates that website of um.edu.my, utm.my, and usm.my had the highest PageRank score seven, followed by uthm.edu.my with PageRank score six and overall ump.edu.my is ranked as worst with PageRank Score Five. From these results, we can conclude that ump.edu.my is very poorly optimized for search engines; therefore, more hard work is required for improving the PageRank score, and position of the website in search engines results in pages.

\section{B. Alexa PageRank}

Alexa PageRank is another vital ranking system set by amazon.com to determine the importance of a web page. According to Alexa officials: the Alexa rank is measured using expected number of page views on the website over the past three months and some expected average every day unique visitors to the website - the website with the highest number of page views and unique customers being ranked as number one.

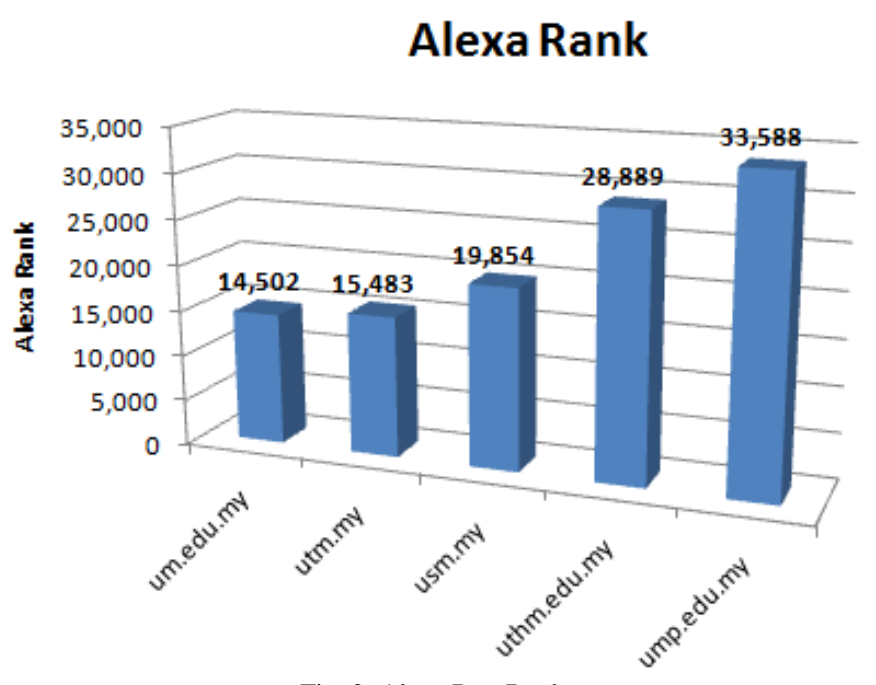

Fig. 2 Alexa PageRank

AlexaRank is the second essential factor by using which we can determine the number of unique visitors to the website every day, and can check if the website is professionally optimized for search engines or not. For a reason, we checked the AlexaRank for all the universities' websites. The lowest AlexaRank score means the website is optimized correctly and professionally, while the highest AlexaRank score means that the website is optimized poorly for search engines and more improvements are required regarding search engines optimization. The AlexaRank score is ranging from 1 to any number. The AlexaRank 1 is the best possible score; it means the website is optimized professionally for search engines and a high number of unique visitors are visiting the website every day.

As we can see in Fig. 2, the website of um.edu.my had the lowest AlexaRank score 14502, while ump.edu.my had the highest AlexaRank score 33588. From universities' AlexaRank scores given in Fig. 2, we can determine that the number of unique visitors per day to these websites is low. A lot more improvement is required regarding SEO for driving unique traffic to all these websites. AlexaRank is dependent on some average unique visitors per day and past three months so results may be different in future.

\section{Woorank Score}

On a 100-point scale, Woorank is dynamic grade, which represents internet marketing efficiency at a given time. In Woorank grade many parameters (mobile rendering, crawl errors, social media data, search engine optimization, search engine results page (SERP) ranking, backlinks, keywords, and visitors, usability and servers optimization, ) are considered, that is why it is considered as a global grade for search engine optimization. Woorank has different color criterion: green means passed, orange if something needs improvement, red is for error and gray means it will not affect SEO score. Woorank can reveal all the issues regarding SEO on any website. 


\section{Woorank Grade}

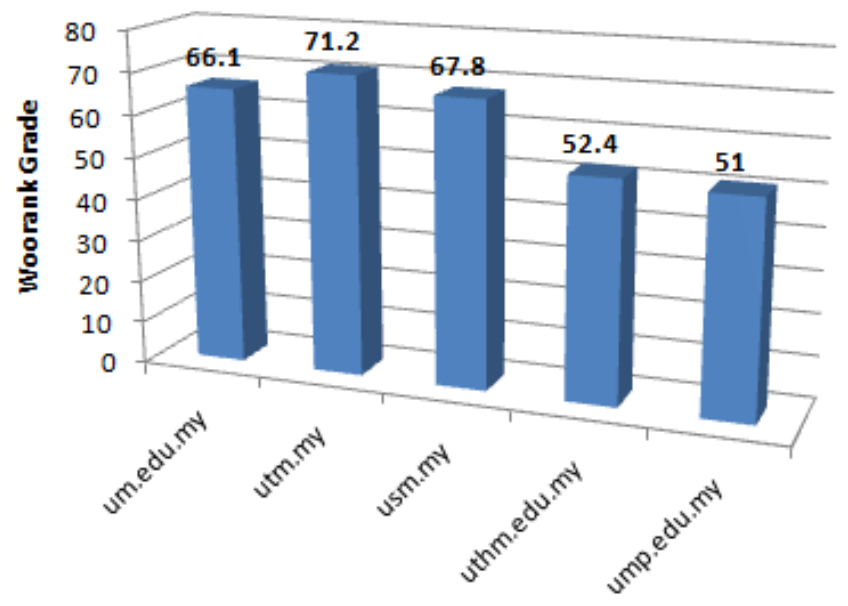

Fig. 3 Woorank score

After calculating the Woorank scores for all five universities, it was found out that the website utm.my had the highest Woorank grade 71.2 as we can see in Fig. 3, while ump.edu.my got the lowest Woorank grade 51, but these scores are dynamic, and results may be different in future. After checking the detailed Woorank reports for all websites, we identified that the results are not satisfactory for all these five websites, and significant improvement is required regarding website usability, mobile speed, mobile friendliness, touchscreen readiness, mobile viewport, website security, page redirect issues, and on-page issues.

\section{Indexed Pages}

Crawler engine is the most critical component of every search engine; these crawler engines scan every page on a website and index all the pages.

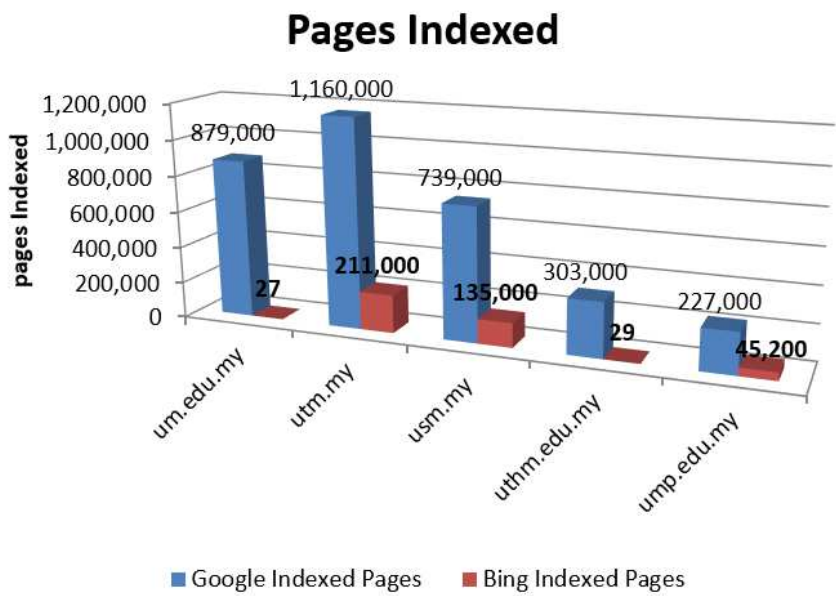

Fig. 4 Page indexed

These indexed pages will show up in search engine results pages and can drive natural traffic to the website. Some indexed pages are changing on a regular basis, but it is one of the most vital factors in search engine ranking. Usually, more indexed pages are considered better. As can be seen in Fig. 4 the website of utm.my had the highest page indexed as compared to others websites. There are 116000 pages of utm.my indexed in Google, and 211,000 pages are indexed in Bing. The website of ump.edu.my had the lowest page indexed as compared to other websites. 227,000 pages are indexed in Google, and 45200 pages are indexed in Bing. We can see other critical results in Fig. 4, a few pages of um.edu.my and uthm.edu.my are indexed in Bing, which means that they did not optimize their websites for Bing. Therefore, more efforts are required by the webmasters of these websites for indexing and optimizing their websites for Bing.

\section{E. Backlinks}

One of the most used words in the world of SEO is backlink. A backlink is also known as incoming links, inbound links, incoming links and inlinks to a web page [27]. When a website links to another web page, it is called an inbound link or backlink. A few years ago, inbound links were the most important factor for website ranking. A web page with too many inbound links will get the higher rank on all important search engines, including Bing and Google. Moreover, still, this is accurate largely [28].

\section{Backlinks}

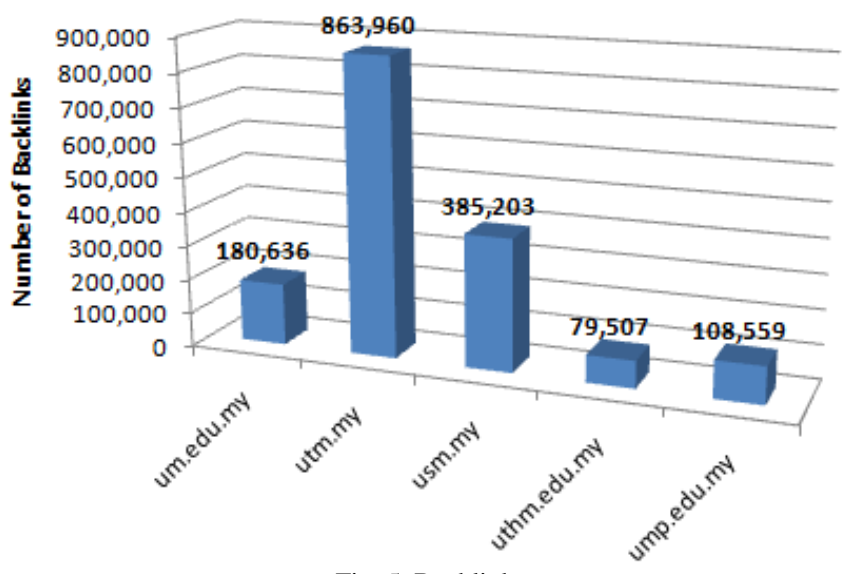

Fig. 5 Backlinks

Google has a stringent policy regarding backlinks. The Google ignores all unimportant or fake links while in the case of Bing, it is less advanced and can easily be cheated by fraudulent links [29]. Fig. 5 illustrates the results with the website of utm.my still had the highest rank in backlinks. The total number of backlinks for utm.my is 863960 . While uthm.edu.my had the lowest rank in backlinks and the total, number of backlinks for uthm.edu.my is 70507. Therefore, Uthm.edu.my needs more good quality backlinks for improving their position in SERP's.

\section{F. Social Media}

Social signals (shares, likes and followers) have a significant influence in search engine optimization. For analysis, we considered two major social networks Twitter and Facebook.

1) Facebook Likes: Facebook significance cannot be overstated in today's web [30]. In the case of Facebook, Bing has an upper hand over Google because Facebook data is not accessible for Google, which is the considerable problem 
Google is facing to keep market domination [31]. Facebook is a vital component of SEO process. It plays a critical role in bringing the website on top in SERP's. Facebook likes for selected Malaysian universities websites are as below:

\section{Facebook Likes}

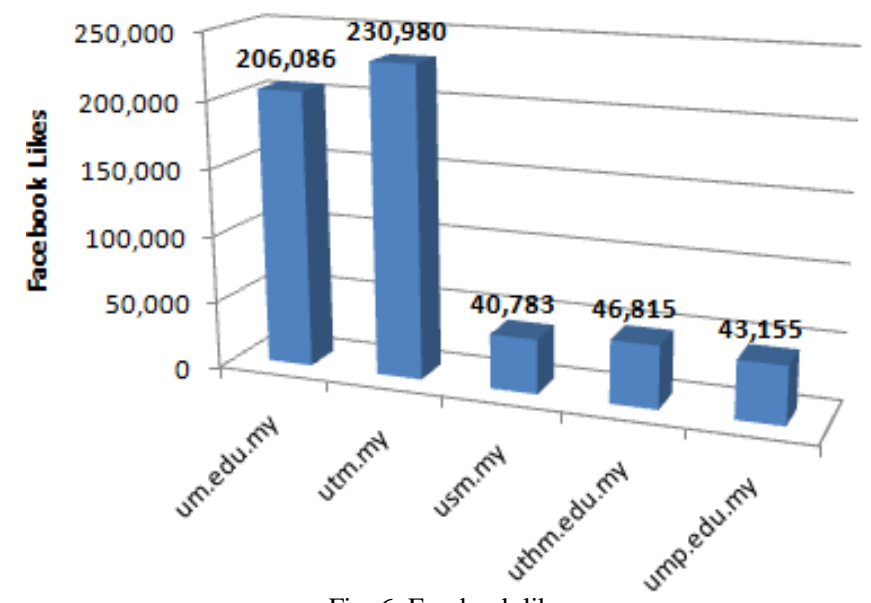

Fig. 6 Facebook likes

In this segment utm.my and um.edu.my dominates on other websites which are the sign of excellent integration of website with social networking sites. In Fig. 6 we can see utm.my is on top with 230980 likes on their fan page, um.edu.my is in the second position with 206086 likes. All other universities' got less than 50k likes on their fan page.

2) Twitter Followers: Twitter data is considered as a vital factor in search results, and to both search engines Google and Bing twitter information are available as paid service.

\section{Twitter Followers}

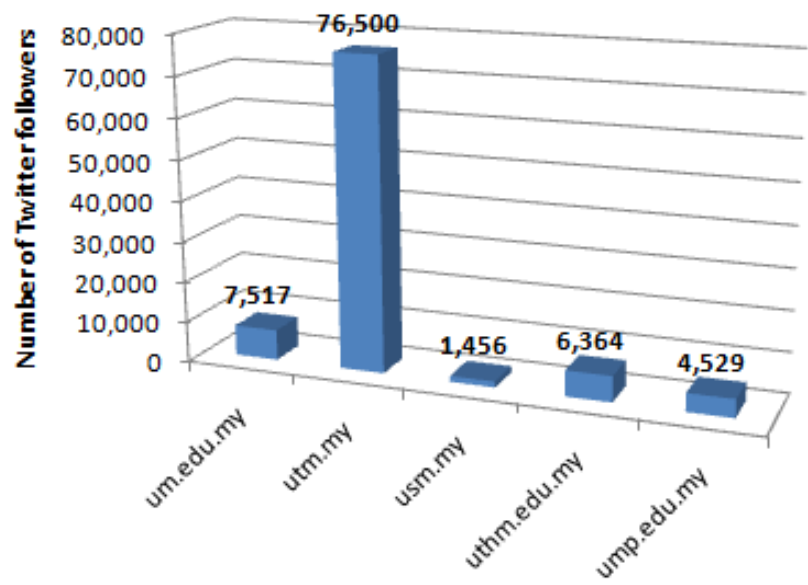

Fig. 7 Twitter followers

Twitter plays the vital role in search engine optimization. In tweets, hashtags are playing the role of keywords; it improves the search ability and helps the other users on Twitter to find these contents. Hashtags can bring the engagement: clicks, likes, and retweets [31]. We can see in Fig. 7 that utm.my dominates in twitter followers. Utm.my got the highest number of twitter followers 76500, while usm.my got the lowest number of twitter followers in 1456 . In these results, we can see that only utm.my focused on the importance of Twitter; all other universities are not giving much attention to the importance of Twitter in search engine optimization.

\section{G. Load Time of Website}

The time required to show the requested website to a user is load time. Higher page load times not only points to many multimedia contents on site but not professionally designed websites. Typically, websites with poor structure, JavaScript and HTML errors, and dirty design are the key factors, which can place the website lower in search engine result pages [32].

\section{Load Time}

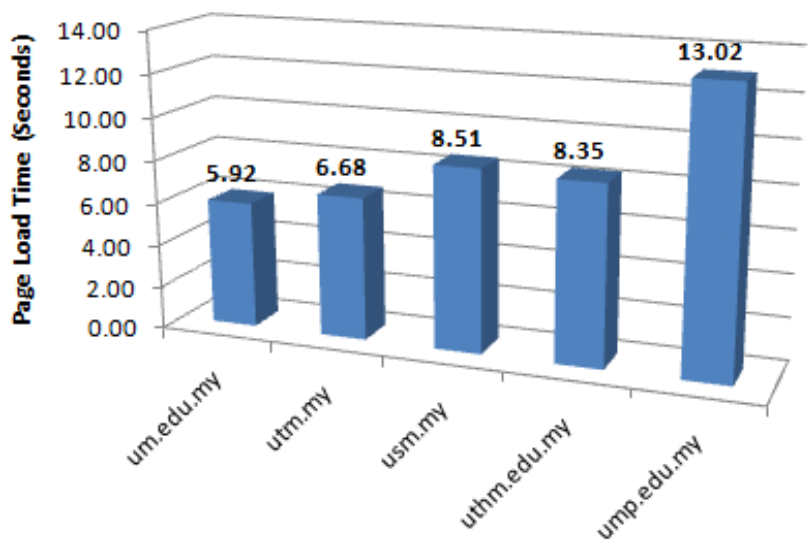

Fig. 8 Load time of the website

Ump.edu.my should ultimately result in lousy search ranking because it has the considerable load time, i.e., 13.02 seconds. It is observed that the sites loading faster are getting 35\% lower bounce rates, $70 \%$ longer average sessions and higher viewability. Technically all five websites are loading slowly because $56 \%$ of website visits are abandoned if a website takes more than 3 seconds to load [32].

Search results ranking for particular Malaysian universities websites are checked for common daily educational search keywords in Malaysia. Keeping sites relevance in mind, all these keywords should rank preferably high in perceived searches, for sure in top hundred. However, in the completed investigation, this was not always the case. Also sometimes, there is a considerable difference between Bing and Google rankings.

The overall results of the experiments are shown in Table 2, ( 0 means the site is not present in first hundred results or first ten search engine results pages). 
TABLE II

SEARCH PHRASE ANALYSIS FOR MALAYSIAN UNIVERSITIES WEBSITES

\begin{tabular}{|l|c|c|c|c|c|c|c|c|c|c|}
\hline Search Phrase & \multicolumn{2}{|c|}{ um.edu.my } & \multicolumn{2}{c|}{ utm.my } & \multicolumn{2}{c|}{ usm.my } & \multicolumn{2}{c|}{ uthm.edu.my } & \multicolumn{2}{c|}{ ump.edu.my } \\
\hline & Google & Bing & Google & Bing & Google & Bing & Google & Bing & Google & Bing \\
\hline ieee conference Date & 0 & 0 & 2 & 0 & 71 & 0 & 0 & 0 & 63 & 0 \\
\hline Bachelor program & 44 & 0 & 8 & 0 & 0 & 0 & 76 & 0 & 84 & 0 \\
\hline $\begin{array}{l}\text { Malaysian University } \\
\text { grants }\end{array}$ & 28 & 38 & 73 & 66 & 20 & 3 & 40 & 77 & 1 & 15 \\
\hline Online Admission & 44 & 26 & 62 & 87 & 1 & 8 & 71 & 0 & 75 & 0 \\
\hline $\begin{array}{l}\text { Admission in PhD } \\
\text { Program }\end{array}$ & 2 & 0 & 48 & 0 & 63 & 0 & 93 & 0 & 0 & 0 \\
\hline Admission Status & 61 & 1 & 89 & 0 & 0 & 0 & 0 & 0 & 0 & 0 \\
\hline $\begin{array}{l}\text { Admission in Master } \\
\text { program }\end{array}$ & 1 & 0 & 57 & 63 & 4 & 0 & 59 & 0 & 88 & 0 \\
\hline
\end{tabular}

\section{CONCLUSION}

This paper had shown in the research results that the targeted websites usually rank lower than they should in the search engine results pages. Initially, we did not consider clean URL is an essential factor in ranking in search engine optimization. However, during this research, we identified that written URL's which contains keywords in it was ranked higher even when initially they were classified as not necessary [26]. Also in 'search phrase analysis' from Table 2, URL's those did not fulfill the human-readable (clean) URL standards ranked lower in the search results.

The outcome of Bing and Google demonstrate that Bing selected websites are ranked worst usually. This is somewhat evidence of the dominance of Google search engine (SE) but also a definite sign that websites are not optimized for Bing and did not take Bing in consideration, even webmasters did not build XML sitemaps for Bing. Improvements in search results are possible with dedicated Bing SEO efforts. Bing cannot be ignored in SEO process because it is the second in search engine (SE) market share. In general, Bing will improve profitability for particular universities websites and will bring more visitors on site.

Overall, the evaluations on search engine optimization (SEO) are done only to some extent on selected websites and have the possibility of more enhancements. Currently, all observed websites are losing potential customers due to unresolved search engine optimization (SEO) problems on site. There is a possibility for enhancement in search engine optimization (SEO) method for investigated Malaysian universities websites.

\section{ACKNOWLEDGMENT}

The authors would like to thank Universiti Tun Hussein Onn Malaysia (UTHM) and Ministry of Higher Education (MOHE) Malaysia for financially supporting this Research under IGSP grants note U420 and under Trans-disciplinary Research Grant Scheme (TRGS) vote no. T003.

\section{REFERENCES}

[1] https://www.google.com/intl/en/insidesearch/howsearchworks/alg orithms.html

[2] Killoran, John B. "How to use search engine optimization techniques to increase website visibility." IEEE Transactions on professional communication 56.1 (2013): 50-66.
[3] R. Kumar and S. Saini, "A study on SEO monitoring system based on corporate website development," International Journal of Computer Science, Engineering and Information Technology (IJCSEIT), Vol.1, No.2, June 2011 pp.42-49.

[4] N. Yalçın and U. Köse, "What is search engine optimization: SEO?", Procedia - Social and Behavioral Sciences, 9, 2010, pp 487-493.

[5] O. Reinhard and D. Johnson, "Search Engine Optimization for the Website of a South African Organization as an Internet Marketing Strategy," Lecture Notes in Engineering and Computer Science, 2012

[6] C. Kerdvibulvech and K. Impaiboon, "A new method for web development using search engine optimization," International Journal of Computer Science and Business Informatics, Vol.3, No.1, July 2013, pp. 1-21.

[7] Yunfeng, Mo. "A study on tactics for corporate website development aiming at search engine optimization." Education Technology and Computer Science (ETCS), 2010 Second International Workshop on. Vol. 3. IEEE, 2010.

[8] Britvic, Ivan, Jurica Duric, and Dalibor Buzic. "Comparative analysis of Google and Bing SEO on leading Croatian news portals." Information and Communication Technology, Electronics and Microelectronics (MIPRO), 2014 37th International Convention on. IEEE, 2014.

[9] 6 SEO trends in 2013 - the quality of content and social signals are on focus, http://itprism.com/blog/107-seo-trends-content-marketing

[10] Gregus, Michal, and Jakub Zilincan. "Improving Rank of a Website in Search Results-An Experimental Approach." P2P, Parallel, Grid, Cloud and Internet Computing (3PGCIC), 2015 10th International Conference on. IEEE, 2015.

[11] Baye, Michael R., Babur De los Santos, and Matthijs R. Wildenbeest. "Search Engine Optimization: What Drives Organic Traffic to Retail Sites?." Journal of Economics \& Management Strategy 25.1 (2016): 6-31.

[12] Baye, Michael R., Babur De los Santos, and Matthijs R. Wildenbeest. "What's in a name? Measuring prominence and its impact on organic traffic from search engines." Information Economics and Policy 34 (2016): 44-57.

[13] X. Xiaojie, F. Yuan, and W. Jian, "The Basic Principles and Applications of the Search Engine Optimization," Proceedings of the 2012 International Conference of Modern Computer Science and Applications Advances in Intelligent Systems and Computing, Vol. 191, 2013, pp 63-69.

[14] S. Duk, D. Bjelobrk, and M. Carapina, "SEO in e-commerce: balancing between white and black hat methods," MIPRO 2013, May 2013, pp. 443-448

[15] Anchor text strategy,

2013, http://www.redmudmedia.com/2013/05/03/seo-anchortextstrategy/\#axzz2wtF5Mb8C

[16] K. Strong, "5 Reasons Why Exact Match Anchor Text is Bad", http://blog.act-on.com/2013/07/5-reasons-why-exact-matchanchortext-emat-is-bad/

[17] S. Anderson, "Free Link Building Tips For 2014", http://www.hoboweb.co.uk/link-building-strategy-for-beginnersa-month-of-free-tips/

[18] N. Patel and B. Dean, "The Advanced Guide to Link Building," http://www.quicksprout.com/the-advanced-guide-to-linkbuildingchapter-1/ 
[19] Webmaster https://support.google.com/webmasters/answer/35769

[20] Bing webmaster

guidelines, https:// $30 \mathrm{fba} 23 \mathrm{a}$

[21] SEO ranking factors - rank correlation 2013 for Bing USA, http://www.searchmetrics.com/en/white-paper/ranking-factorsbing/

[22] J. Sherrod, "SEO for Bing - Google and Bing indexing differences," http://www.searchdiscovery.com/blog/seo-for-bing-google-andbingindexing-differences/

[23] Bing optimization, http://www.webconfs.com/bing-optimizationarticle-25.php

[24] StatCounter global stats http://gs.statcounter.com/\#all-search_engineHR-monthly-201301201312-bar

[25] M. McGee, "Bing Ends 2013 With All-Time High In US Market Share, But Google Also Up [comScore]", http://searchengineland.com/bing-ends-2013-with-all-time-highin-usmarket-share-but-google-also-up-comscore-181876

[26] Su, Ao-Jan, et al. "How to improve your Google ranking: Myths and reality." Web Intelligence and Intelligent Agent Technology (WI-IAT), 2010 IEEE/WIC/ACM International Conference on. Vol. 1. IEEE, 2010 .
[27] Lynn, Theo, Malcolm Brady, and Ieva Masevic. "A risk assessment method for negative SEO attacks using a game theoretic approach." Professional Communication Conference (IPCC), 2015 IEEE International. IEEE, 2015.

[28] Zhao, Chunshui, Jun Yan, and Ning Liu. "Improve Web Search Ranking by Co-Ranking SVM." Natural Computation, 2008. ICNC'08. Fourth International Conference on. Vol. 2. IEEE, 2008.

[29] Zhang, Sonya, and Neal Cabage. "Search Engine Optimization: Comparison of Link Building and Social Sharing." Journal of Computer Information Systems 57.2 (2017): 148-159.

[30] Baye, Michael R., Babur De los Santos, and Matthijs R. Wildenbeest. "Search engine optimization: what drives organic traffic to retail sites?." Journal of Economics \& Management Strategy 25.1 (2016): 6-31.

[31] Kini, Pavan, et al. "Managing search-engine-optimization content in web pages." U.S. Patent No. 9,659,095. 23 May 2017.

[32] Londhe, Shraddha, and Hemant Deshmukh. "Review Paper on Search-Engine Optimization." International Journal of Engineering Science 10524 (2017). 